\title{
La Unción: Uma mirada histórica y sociológica al fenómeno que avivó la Iglesia Argentina desde 1992
}

\author{
La Unción: \\ A historical and sociological \\ look in the phenomenon that stoked the Church \\ Argentina since 1992
}

Roney de Seixas Andrade

J. Gabriel Raimondo

\section{Resumen}

Este ensayo propone investigar el contexto histórico inmediato que llevó al renuevo espiritual originado en 1992 en Buenos Aires, Argentina; fenómeno popularmente conocido como "La Unción". Para esto, se buscará periodizar los sucesos que precedieron dicho evento, como también evaluar los frutos que en el correr de los años se han recogido. Asimismo, se intentará observar la función de la experiencia en la praxis cristiana con relación a la misión y la liturgia. Finalmente se elaborarán conclusiones críticas que pongan en la balanza este fenómeno con la intención de aportar un paradigma de renovación espiritual.

Palabras-claves: Argentina. El evangelismo. El pentecostalismo. La Unción.

\section{Abstract}

This paper intends to investigate the immediate historical context that led 
to spiritual renewal originated in 1992 in Buenos Aires, Argentina; phenomenon popularly known as "La Unción". For this, we will seek periodize the events that preceded the event, as evaluating the fruits in over the years they have been collected. Additional attempts to observe the function of experience in Christian praxis regarding the mission and liturgy. Finally critical findings put in the balance this phenomenon with the intention of providing a parading of spiritual renewal will be developed.

Keywords: Argentina. Evangelicalism. Pentecostalism. La Unción.

\section{Introducción}

El suelo argentino ha experimentado, en las últimas dos décadas del siglo pasado, una serie de cambios en la atmosfera espiritual del cristianismo. En un país cuya predominancia católica daba poco margen a que el pueblo evangélico se extienda a nuevas fronteras, luego de las heridas de un período de dictadura militar y de la guerra por las Islas Malvinas (1982), un viento fresco comenzó a soplar desde el seno de la iglesia pentecostal. Allí, por el comienzo del gobierno democrático, en los inicios de la década del ochenta, miles y miles se acercaban a los pies del Jesucristo predicado por un evangelista de barrio bonaerense. Multitudes eran salvas, libres espiritualmente, sanas y llenas del Espíritu Santo. Las iglesias no podían ni sabían contener esta pesca milagrosa. Luego de unos años, la preparación para el creyente parecía llegar, esta vez cuando un pastor porteño (del centro bonaerense) gritaba: "reciban la unción." La iglesia, entonces, se mostró lista para avanzar con el reino de Dios a horizontes desconocidos.

Este ensayo propone investigar el contexto histórico inmediato que llevó al renuevo espiritual originado en 1992 en Buenos Aires, Argentina; fenómeno popularmente conocido como "la unción". ${ }^{1}$ Para esto, se buscará periodizar los sucesos que precedieron dicho evento, como también evaluar los frutos que en el correr de los años se han recogido. Asimismo, se intentará observar

\footnotetext{
'Se hará referencia a "la unción" como frase representativa del despertar espiritual originado a partir de 1992. Sin embargo, utilizaremos simultáneamente términos tales como "avivamiento" o "despertar espiritual" con la misma intención. La idea que se pretende reflejar al usar esta terminología es la de períodos de tiempo en los cuales ha habido un interés masivo hacia el evangelio o aspectos de la iglesia evangélica.
} 
la función de la experiencia en la praxis cristiana con relación a la misión y la liturgia. Finalmente se elaborarán conclusiones críticas que pongan en la balanza este fenómeno con la intención de aportar un paradigma de renovación espiritual.

Para lograr los objetivos previamente trazados, se echará mano a la investigación de fuentes históricas primarias y secundarias, y éstas debidamente citadas. De esta manera, obtendremos extractos de videos pertinentes al tema los cuales funcionen como ilustración, o bien, como soporte de algún punto en mención. Asimismo, consultaremos literatura orientada a este tema y período de tiempo en Argentina; material bibliográfico de fuentes eruditas y otras basadas en las experiencias de quienes las vivieron.

La metodología a utilizar consta del método histórico y sus cuatro etapas, a saber, 1) la etapa heurística, en la cual se trabajará con el material bibliográfico disponible $\mathrm{y}$, a través del momento erudito y diagnosis, se priorizará lo pertinente a la tesis central del ensayo; 2) la etapa crítica, en la cual se analizará cualitativamente las fuentes para luego interpretarlas históricamente a través de la sospecha ideológica (momento hermenéutico); 3) la etapa de síntesis, en la cual se ordenará el material coherentemente con el fin de crear una periodización; y 4) etapa expositiva, en donde se presentará un análisis crítico y los resultados de la investigación.

Debido a que la expansión de este fenómeno espiritual no siguió una línea denominacional ni mantuvo una identidad inmutable, sino más bien su avance fue de características orgánicas e inter-denominacionales, nos remitiremos a estudiar la historia del fenómeno sin seguir los lineamientos históricos de cada iglesia o denominación en especial; aunque dedicaremos particular atención a una línea histórica de personalidades que desembocaron en lo sucedido en la iglesia Rey de Reyes del pastor Claudio Freidzon (perteneciente a la Unión de las Asambleas de Dios). El período que se pretende analizar está comprendido entre los años 1954 a 1992, aunque nos concentraremos en los años 1982 a 1992, y en el contexto argentino específicamente. Por motivos de extensión, no trataremos las raíces históricas globales que antecedieron a este fenómeno durante los siglos XIX y XX; raíces que deberían remontarse al ministerio de Juan Wesley, a las enseñanzas de Charles F. Parham, y, en especial, al conocido avivamiento de la calle Azusa con William Seymour. ${ }^{2}$ Nos concentraremos,

\footnotetext{
${ }^{2}$ En cuanto a literatura afín al origen del pentecostalismo, véase, entre otras fuentes, las siguientes: ROBECK Jr., C. M. The Azusa Street Mission and Revival, The Birth of the Global Pentecostal Movement. Nashville, TN: Thomas Nelson, 2006. Para referencias del
} 
sin embargo, en el trasfondo histórico del pentecostalismo en Argentina, y con más detalle, a los eventos contiguos al despertar de 1992.

El presente ensayo pretenderá responder a preguntas tales como ¿cuáles fueron los posibles factores por los que este fenómeno tomó lugar en la Argentina de 1992, y por qué ocurrió con el pastor Claudio Freidzon?, ¿qué hizo que la unción se expanda tan rápidamente?, ¿cómo cambió la vitalidad de la iglesia evangélica a partir de la unción?, ¿cómo ha evolucionado este fenómeno?, ¿cuáles son los desafíos teológicos, eclesiológicos y misiológicos que quedan por delante?

\section{De los principios al despertar}

Para hablar de la historia de "la unción", debemos comprender que existió un contexto histórico previo que plantó la semilla pentecostal. Las iglesias pentecostales argentinas no gozaban de gran popularidad hasta principios de 1980, y se las veía más como sectas que como cristianismo per se. Para hacer justicia a dicho contexto, podemos trazar las primeras apariciones pentecostales en Argentina a pocos años después del famoso irrumpir espiritual de la calle Azusa en el año 1906. Fue en 1909 cuando las primeras experiencias pentecostales aparecen en tierras argentinas de la mano de tres italoamericanos, Luis Francescon, Giacomo Lombardi y Lucía Menna. Estos misioneros, provenientes de una iglesia italiana en Chicago, al recibir la experiencia pentecostal deciden ir a compartirla a Buenos Aires guiados por una revelación divina. ${ }^{3}$ Francescon luego se fue a continuar su obra en Brasil, en donde predicaba en la Iglesia Presbiteriana de São Paulo y ante tensiones y roces, se separó del presbiterianismo y fundó la Congregação Cristã do Brasil, la cual para 1965 contaba con 270.000 miembros bautizados. ${ }^{4}$ Lo innovador de este movimiento, sumado a la vitalidad y dependencia de Dios de estos pioneros pentecostales, realmente atraía gente que quería algo más que una

pentecostalismo norteamericano y su temprana expansión en América Latina, consultar: PRIEN, H. J. La historia del cristianismo en América Latina. Salamanca, España: Ediciones Sígueme, 1985 y también DEIROS, P. A.; MRAIDA, C. Latinoamérica en llamas, Historias y creencias del movimiento religioso más impresionante de todos los tiempos. Nashville, TN: Editorial Caribe, 1994.

${ }^{3}$ DAVIES, W. W. The Embattled but Empowered Community, Comparing Understanding of Spiritual Power in Argentine Popular and Pentecostal Cosmologies. Leiden, The Netherlands: Kominklijke Brill, 2010, p. 91.

${ }^{4}$ PRIEN, H. La historia del cristianismo en América Latina, p. 825. 
religión. Estas raíces comenzaron a marcar un camino que poco a poco se iba abriendo paso en Argentina (y en todo Latinoamérica). Con los estandartes de las visiones, las lenguas y el poder de Dios la historia se empezaba a escribir.

En Noviembre de 1916 Narciso Natucci, perteneciente a la misma iglesia de Francescon en Chicago, y Francisco Anfuzzo llegaron a Buenos Aires con la finalidad de continuar la obra que Francescon había comenzado entre los inmigrantes italianos, y comenzaron una pequeña iglesia en el centro de Buenos Aires con algunos familiares de Anfuzzo. ${ }^{5}$ En la década de 1920 la obra se extendió entre inmigrantes italianos de todo el país, constituyendo iglesias pentecostales de habla italiana que funcionaban como refugio de identidad cultural. ${ }^{6}$ Para 1947 se había formado la Unión de las Asambleas de Dios, que resultó de la unificación de las Asambleas de Dios de los Estados Unidos a la que se juntaron la Asamblea Pentecostal de Canadá y la Iglesia Pentecostal de la Santidad. ${ }^{7}$

El próximo momento histórico observable, que bien podemos decir que marcó un antes y un después en el pentecostalismo argentino, fueron las campañas de sanidad del evangelista norteamericano Tommy Hicks en el año 1954. A lo largo de ocho semanas se desarrollaron multitudinarias campañas de sanidad, algo totalmente inusual y nunca antes visto en suelo argentino, que atrajo la atención de naciones y llevó al crecimiento de muchas iglesias, particularmente de la Unión de las Asambleas de Dios (UAD). ${ }^{8}$ Rocky Grams, misionero norteamericano en Argentina, dice: "Es estimado que dos millones de personas escucharon el evangelio ¡en menos dos meses! Dios ha cumplido su promesa. La última tarde de la campaña más de doscientas mil personas se reunieron para escuchar al evangelista y para ser testigos de las maravillas de Dios". 9

Es interesante notar la manera en que estos pioneros pentecostales se movían en su ministerio, patrón que siguieron aquellos que mencionaremos más adelante. Especialmente las campañas de Hicks han venido a ser un modelo a seguir. Su ministerio dejó claro que en Argentina se puede alcanzar las multitudes con un evangelio de poder y milagros. Se le ha preguntado al

${ }^{5}$ SARACCO, J. N. Argentine Pentecostalism, Its History and Theology. Tesis de PhD, Universidad de Birmingham, 1989, p. 47.

${ }^{6}$ Ibid., p. 48.

${ }^{7}$ DAVIES, W. W. The Embattled but Empowered Community, p. 93.

${ }^{8}$ Ibid., p. 95.

${ }^{9}$ GRAMS, R. In Awe in Argentina. Lake Mary, FL: Creation House, 2006, p. 36. 
evangelista Hicks el motivo por el cual iba a Argentina, cuál era la razón por lo que escogía esa nación para evangelizar, sabiendo de su trasfondo católico romano y que nunca antes se habían realizado eventos masivos. En su propio reporte del avivamiento argentino, Tommy Hicks responde en sus palabras:

Fue mientras estaba en el avión que me di cuenta que iba a Argentina, y no tenía idea que me esperaba delante $[. .$.$] pero Dios puso esto en mi$ corazón, y cuando el gran avión Pan Agra volaba en cielo argentino, vino a mi mente y a mi corazón un deseo urgente que tenía que ver al presidente argentino. Mientras pensaba en esto, vino a mi mente el nombre Perón, y yo no sabía que el señor Perón era el presidente de Argentina; y una y otra vez venía a mí el nombre de Perón, Perón. ${ }^{10}$

Es así que por sus propios medios se encuentra con el presidente Perón quien, por escrito, le otorga el acceso libre para mantener reuniones multitudinarias en el estadio de Atlanta como también uso libre y gratuito de la prensa y la radio. ${ }^{11}$ Michael Donald Richardson, en su disertación doctoral "Lessons from the Revival on Argentina", apunta que "los católicos quedaron atónitos, y algunos sugieren que el presidente estaba sacando ventaja de la presencia de Hicks para ponerse en contra de la iglesia católica la cual estaba dejando de apoyarlo". ${ }^{12}$ La campaña se abrió el 14 de Abril de 1954, y había comenzado con poco menos de 1000 personas, pero con las noticias de las impactantes sanidades, las multitudes comenzaron a acercarse de a miles y miles. ${ }^{13} \mathrm{~A}$ partir de estas campañas podemos decir que la iglesia evangélica pentecostal dejó el margen para buscar un rol protagónico en la sociedad, aunque no con un crecimiento significativo, quizás debido a tiempo de las dictaduras militares.

De Hicks debemos dirigirnos al próximo momento expansivo, y al que prestaremos más atención dado a que está ligado directamente a la era de la unción. Esta época la podemos observar a partir de los ministerios del pastor Omar Cabrera, y, especialmente, del evangelista Carlos Annacondia. No hablaremos del llamado "movimiento carismático" que surge en Argentina

\footnotetext{
${ }^{10}$ HICKS, T. Millions Found Christ, Greatest Recorded Revival. Hollywood, CA: International Headquarters of Tommy Hicks, 1956, p. 13.

${ }^{11}$ Ibid., pp. 14-15.

${ }^{12}$ RICHARDSON, M. D. Lessons from the Revival on Argentina. Tesis para un Doctorado en Ministerio. Fuller Theological Seminary, Pasadena, CA, 1998, p. 34.

${ }^{13}$ Ibid., pp. 34-35.
} 
entre la década del sesenta y setenta. Basta decir para nuestros fines, que este movimiento incluyó líderes de vastas denominaciones, pero particularmente Católicos Romanos. La búsqueda del renuevo espiritual, el cual experimentaban en sus reuniones, marcaba un futuro carismático para la iglesia en general, y un deseo de renovación espiritual que buscaba respuesta divina.

\section{La antesala a la unción}

Hubo dos referentes innegables en Argentina para varios pastores que anhelaban un renuevo espiritual y crecimiento en sus iglesias. El pastor Omar Cabrera y el evangelista Carlos Annacondia fueron precursores del despertar que estaba por vivir la iglesia Argentina. Dediquemos atención a esta antesala de la unción. Observaremos en esta sección los eventos evangélicos pentecostales que tomaron lugar desde fines de la década del sesenta hasta la década del ochenta.

En 1968 Omar Cabrera comenzó una pequeña iglesia en la provincia de Entre Ríos con un grupo de 14 personas, y en un año crecieron a 120. ${ }^{14}$ Motivado por los eventos masivos de Tommy Hicks en 1954 de los cuales él fue testigo, ${ }^{15}$ el 25 de Octubre de 1969 Cabrera se aventuró a comenzar una campaña ${ }^{16}$ evangelística programada para durar 15 días, pero que se extendió por 540 días seguidos, comenzando con una asistencia de unas 500 personas y alcanzando unas 15.000 en el período de dos semanas. ${ }^{17}$ Estas reuniones se caracterizaban por la manifestación sobrenatural de Dios, especialmente expresada en milagros de sanidad física. Para el final de estas reuniones, el agotamiento lo llevó a tomarse un descanso de un año y medio a los Estados Unidos, en donde el Espíritu Santo le mostró que debía continuar su ministerio en Argentina, pero orientado a ganar a Católicos Romanos nominales. ${ }^{18}$ Es así que creó el ministerio Visión de Futuro como una iglesia independiente

\footnotetext{
${ }^{14}$ Ibid., p. 40.

${ }^{15}$ WAGNER, C. P.; DEIROS, P. A. Manantiales de avivamiento: lo que el Espiritu dice a través del avivamiento en Argentina. Nashville, TN: Editorial Caribe Betania, 1998, p. 63.

${ }^{16}$ Se usa el término "campaña" o "cruzada" desde la comprensión popular evangélica refiriéndose a los eventos evangelísticos de conversión masiva. Se entiende, sin embargo, que estos términos deberían conllevan una connotación negativa que pueden apuntar a campañas o cruzadas militares de la iglesia católica romana medieval. Pero, con ingenuidad o no, ha quedado popularmente aceptado esta terminología que usamos en este ensayo.

${ }^{17}$ RICHARDSON, M. D. Lessons from the Revival on Argentina, p. 40.

${ }^{18}$ WAGNER, C. P.; DEIROS, P. A. Manantiales de avivamiento, p. 63.
} 
en 1972 experimentado un gran crecimiento para la época, pero excediendo toda expectativa desde 1979 a 1985 , cuando creció de 30.000 a 145.000 personas. ${ }^{19}$ Con un ministerio tan innovador y creciente, marcado por el poder sobrenatural de Dios, Omar Cabrera estaba abriendo camino a los próximos momentos de renuevo espiritual.

Por su lado, la vida cristiana de Carlos Annacondia, un exitoso hombre de negocios, comienza cuando en 1979 asiste a una reunión pentecostal del evangelista panameño Manuel A. Ruiz en la ciudad argentina de San Justo. ${ }^{20}$ Asistió a este evento por pura curiosidad dado a que había oído que Ruiz echaba fuera demonios; y en esta reunión se convierte a Cristo. ${ }^{21}$ El ministerio del evangelista Annacondia comienza inmediatamente después de su conversión guiado por su pastor Jorge Gomelski. Comenzó evangelizando en lugares muy pobres (llamados villas miserias en Argentina), visitando hospitales y orando por todos los enfermos. ${ }^{22}$ Carlos Annacondia relata el llamado al ministerio en sus palabras:

Cuando Dios me dio el ministerio, Él me preguntó: “¿Estás dispuesto a pagar el precio?" El precio por mi ministerio no era algún sacrificio que yo tenía que hacer para que Dios me lo diera. El precio era llevar sobre mis hombros la carga y responsabilidad de ese ministerio, lo cual significaba abandonar el hogar, no estar con los hijos, enfrentar críticas y oposición, tener que poner dinero de mi bolsillo, etc. [...] Yo le pedí al Señor: “¡Úsame! ¡Úsame!” Y Dios me contestaba: "Ve a las villas miserias, y entrégame tu negocio." ${ }^{23}$

Fue así que dejó su negocio y se aventuró al ministerio a los lugares carenciados guiado por lo que él decía ser la voz de Dios. Es interesante notar esta dinámica espiritual en las personalidades que hemos observado, caracterizada por la guía directa de Dios hablándoles continuamente. Esto era atractivo. Ellos mostraban a un Dios activo, interesado en cambiar vidas. Dios

19 MÍGUEZ, D. Spiritual Bonfire in Argentina, Confronting current Theories with an Ethnographic Account of Pentecostal Growth in a Buenos Aires Suburb. Amsterdam, Holanda: CEDELA, 1989, p. 29.

${ }^{20}$ DEIROS, P. A. Historia del Cristianismo en América Latina. Buenos Aires, Argentina: Fraternidad Teológica Latinoamericana, 1992, p. 172.

${ }^{21}$ DAVIES, W. W. The Embattled but Empowered Community, p. 100.

${ }^{22}$ WAGNER, C. P.; DEIROS, P. Manantiales de avivamiento, p. 83.

${ }^{23}$ Ibid., pp. 82-83 (palabras de Carlos Annacondia). 
no estaba ajeno a todo, no estaba callado. No colgaba indefenso de una cruz. $\mathrm{Y}$ con esta convicción estas personas actuaban sin barreras.

En el año 1980, Carlos Annacondia comienza un programa radial llamado "Mensaje de salvación." A partir de este programa y su ministerio en las villas miserias, se inician campañas evangelísticas en varios barrios carenciados de la ciudad de Buenos Aires. Estas reuniones, realizadas en grandes carpas levantadas en terrenos descampados, cobraron popularidad por su énfasis sobre sanidad física, liberación espiritual, y caídas, además de un mensaje evangélico sencillo orientado a un llamado de salvación. ${ }^{24}$ Debido a esto, las multitudes no tardaron en hacerse presente. Al mejor estilo campestre argentino, con parrillas alrededor de las carpas que preparan choripanes (sándwich de chorizo con salsa típica argentina llamada chimichurri), y con tiendas aledañas en donde se oraba por aquellos que necesitaban liberación espiritual, estas campañas comenzaron a ser todo un éxito.

A partir del año 1981, las campañas comenzaron a realizarse una tras otra, y en el cuadro que sigue, se refleja las decisiones de fe por Cristo: ${ }^{25}$

\begin{tabular}{|l|c|c|}
\hline \multicolumn{1}{|c|}{ Lugar } & Año & Decisiones de fe \\
\hline 1. Don Bosco (Beccar) & 1981 & 110 \\
\hline 2. Villa Domínico & 1982 & 100 \\
\hline 3. Florencio Varela (Alpargatas) & 1982 & 70 \\
\hline 4. Florencio Varela (Barrio San Eduardo) & 1982 & 279 \\
\hline 5. Quilmes (Kolynos) & 1983 & 700 \\
\hline 6. Don Bosco (Beccar) & 1983 & 1.000 \\
\hline 7. Ezpeleta & 1983 & 350 \\
\hline 8. Bernal (IAPI) & 1983 & 750 \\
\hline 9. Francisco Solano & 1983 & 700 \\
\hline 10. Quilmes Oeste & 1983 & 800 \\
\hline 11. Wilde & 1983 & 1.500 \\
\hline 12. Bosques & 1983 & 600 \\
\hline
\end{tabular}

${ }^{24}$ DEIROS, P. A. Historia del Cristianismo en América Latina, p. 172.

${ }^{25}$ WAGNER, C. P.; DEIROS, P. Manantiales de avivamiento, p. 85. 


\begin{tabular}{|l|c|c|}
\hline 13. Tres Arroyos & 1983 & 100 \\
\hline 14. Berisso & 1984 & 2.000 \\
\hline 15. Ranelagh & 1984 & 1.600 \\
\hline 16. City Bell & 1984 & 1.700 \\
\hline 17. La Plata, Ensenada y Tolosa & 1984 & 50.000 \\
\hline 18. Monte Grande & 1984 & 8.500 \\
\hline 19. Lomas de Zamora & 1984 & 1.800 \\
\hline 20. Mar del Plata & 1984 & 83.000 \\
\hline 21. San Justo & 1985 & 60.200 \\
\hline 22. San Martín & 1985 & 57.000 \\
\hline 23. Moreno & 1985 & 16.000 \\
\hline
\end{tabular}

Las reuniones del evangelista Annacondia han recibido un amplio respaldo multi-denominacional, y muchas iglesias deben su crecimiento a ellas. Debido a la popularidad de estas campañas, su ministerio ha logrado un alcance internacional. Localmente, Carlos Annacondia fue uno de los referentes más buscados por pastores y líderes evangélicos como inspiración para sus ministerios. Entre estos pastores, se encontraba Claudio Freidzon, un joven ministro de la Unión de las Asambleas de Dios que fervientemente deseaba un cambio en su ministerio. A continuación consideraremos la búsqueda del pastor Claudio Freidzon y la experiencia que transformó su ministerio y espiritualidad de la iglesia evangélica argentina.

\section{De la búsqueda personal a la unción}

Por el año 1977 Claudio Freidzon se graduaba del seminario bíblico IBRP (Instituto Bíblico Río de la Plata) y comenzó a pastorear una iglesia pequeña en un barrio de la ciudad bonaerense llamado Parque Chás. Ante la frustración de que su evangelismo no atraía a la gente a Cristo, sino solo unas pocas ancianas que se mantenían fieles, piensa en dejar el ministerio. El pastor Freidzon lo expresa con estas palabras:

Lo que más me dolía era ser un pastor sin ovejas. Durante siete años mi congregación no superaba las siete personas. En algunos cultos yo estaba 
solo, sin siquiera mi esposa. A veces venían pastores amigos a presenciar el culto y me encontraban sólo. Sentía ganas de morir, de desaparecer. Me consideraba una víctima... Caminaba entre los bancos vacíos y el diablo saltaba riendo a mi alrededor y me susurraba al oído: "No sirves, jamás vas a progresar, esto siempre será así». Y lamentablemente le creía. Un día pensé: «Esto no es para mí. Voy a renunciar al pastorado. Voy a continuar mis estudios de ingeniería y buscarme un empleo." Pero íntimamente sabía que ese no era el plan de Dios. ${ }^{26}$

Luego de visitar al superintendente para entregar sus credenciales de ministro, ante su sorpresa, recibió el aliento necesario para continuar con su ministerio. Ya comenzando la década del ochenta, el ministerio del evangelista Carlos Annacondia estaba trayendo grandes expectativas en el ambiente evangélico. Las manifestaciones y las multitudes renovaban la esperanza a pastores que querían un cambio, y en el ministerio de Annacondia lo veían posible. Este fue el caso de Claudio Freidzon, quien ante la sequedad ministerial, buscó desesperadamente el renuevo que se presentaba en el ministerio del conocido evangelista. En una entrevista al pastor Freidzon, él expresó al respecto:

Yo fui a verlo a Annacondia siendo un pastor jovencito de una iglesia de quince personas, a decirle si yo podía, con mucho respeto, con mucho temor, ir a su casa. Le dije: "yo sé que usted es un hombre muy usado, muy conocido; yo soy nadie, pero yo quiero ir a su casa, quiero orar con usted, y quiero que lo que usted tiene venga sobre mí, que lo que Dios le dio a usted también me lo dé a mí." Así que estuve un año yendo a la iglesiade él [a las reuniones evangelísticas] y él por un año estuvo orando por mi ministerio, por mi familia, por mi iglesia muy pequeña, por mi ciudad, y eso fue generando, en mí, cambios. ${ }^{27}$

En 1985, como resultado de estos cambios, y motivado por una visión de Dios, Claudio Freidzon comenzó unas reuniones evangelísticas en Plaza

\footnotetext{
${ }^{26}$ FREIDZON, C. Espíritu Santo, tengo hambre de ti. Nashville, TN: Caribe-Betania, 1996, pp. 29-30.

${ }^{27}$ Transcripción de una entrevista realizada al pastor Claudio Freidzon por el Ministerio Conexión Vida (Venezuela, perteneciente al pastor Félix Parra) en el año 2008, y publicada en YouTube el 24 de Julio de 2012. Disponible en: <http:/www.youtube.com/watch?v=g8rm9p94CiA>. Acceso en 02 de diciembre de 2014.
} 
Noruega, en el centro de Belgrano, Buenos Aires. A lo largo de tres semanas de campaña, 1.300 personas aceptaron a Cristo, diez veces más que el tamaño de su iglesia en ese momento. ${ }^{28}$ Así nace la iglesia Rey de Reyes en el barrio de Belgrano.

Para el año 1992, teniendo una iglesia relativamente grande y estable, el pastor Freidzon siente un deseo de una nueva renovación. Una sed espiritual se presenta nuevamente en su vida. En sus palabras dice: "Dios vertió un salero en mi lengua. Me dio una sed espiritual intensa que necesitaba saciar. ¡Hambre del Espíritu Santo!”29 Influenciado por el libro Buenos días Espíritu Santo - del evangelista norteamericano Benny Hinn - decide viajar a los Estados Unidos en búsqueda de una renovación espiritual. El evangelista Hinn ora por el pastor Freidzon, éste recibe una experiencia espiritual y una profecía que su ministerio impactaría naciones. Para su sorpresa, al regresar a su iglesia en Buenos Aires, muchos en su congregación caían durante los servicios bajo la unción y recibían milagros extraordinarios. ${ }^{30}$ Es en ese momento comienzan un serie de experiencias que atrajeron la atención de literalmente multitudes de toda variedad denominacional.

Se realizaron reuniones en diferentes estadios de Buenos Aires y el país, en donde la gente era renovada espiritualmente por la unción. Volvían a sus iglesias con nuevo vigor espiritual, con deseos de orar, con un compromiso con Dios renovado, y movidos a salir a las calles a llevar el mensaje de salvación en Cristo. El historiador Pablo A. Deiros define este fenómeno de la siguiente manera:

Más allá de las consideraciones históricas, los análisis sociológicos y las evaluaciones culturales, algunos historiadores cristianos vemos a lo largo de este período en estudio el desarrollo de un proceso profundo de renovación espiritual en el protestantismo latinoamericano. Hacia 1992 comenzó en Argentina una ola de avivamiento caracterizado por "manifestaciones" (señales del Espíritu Santo), que pronto se extendieron a lo largo y a lo ancho de todo el continente, y finalmente llegaron a todo el mundo. El pastor Claudio Freidzon reunió a grandes multitudes de evangélicos en estadios de la ciudad de Buenos Aires, donde por su ministración, las personas recibían la "unción del Espíritu Santo," con

\footnotetext{
${ }^{28}$ GRAMS, R. In Awe in Argentina, p. 94.

${ }^{29}$ FREIDZON, C. Espiritu Santo, tengo hambre de ti, pp. 74-75.

${ }^{30}$ GRAMS, R. In Awe in Argentina, p. 96.
} 
manifestaciones como caídas, mareos, risa, temblores y otras expresiones físicas. $^{31}$

A estas manifestaciones espirituales se las entendía dentro del concepto bíblico de la unción del Espíritu Santo. El sociólogo Hilario Wynarczyk, en su estudio del movimiento evangélico argentino entre 1980 y 2001, señala que frases como la "unción fresca" y "frescura espiritual" aluden metafóricamente a la experiencia de "recibir una nueva gracia de Dios que refresca la iglesia conservadora y adormecida." 32 Para explicar la unción, Wynarczyk primeramente la define como una variante de la lluvia tardía en los días postreros. Lo característico de este mover es que la unción es derramada por el Espíritu Santo sobre un predicador; luego este predicador puede trasmitirla a otro pastor, de manera que este pastor puede llevar la unción a su iglesia, y esta iglesia al recibirla comienza a experimentar un nuevo estilo de vida cristiana, con más entusiasmo y milagros. ${ }^{33}$ Freidzon incorporó a su estilo de ministerio prácticas similares a las usadas por Benny Hinn. La unción se soltaba sobre personas o grupos que caían al suelo, se soplaba o se arrojaba el saco para recibirla, se marcaba un círculo imaginario en la plataforma en el que las personas, cuando entraban, caían por el poder de Dios, ${ }^{34}$ y modalidades similares a estas caracterizaban los servicios que la gente deseaba visitar con el fin de experimentar este nuevo fenómeno.

El mensaje se centraba en una relación íntima y profunda con el Espíritu Santo. Como resultado de esto, las iglesias evangélicas comenzaron a crecer significativamente. Miles se convertían a Cristo. Para este entonces, las iglesias evangélicas se transformaron en centros de renuevo espiritualmás que en templos de predicación. Pastores de diferentes denominaciones históricas llevaban estas experiencias a sus iglesias, que salían del formalismo religioso a la libertad del Espíritu Santo. Eran verdaderas fiestas espirituales, si se pudieran llamar así. De hecho, el ambiente era de fiesta y alegría. La gente se desesperaba por ir a la iglesia. Fue este el caso de la iglesia Rey de Reyes, en donde filas interminables de personas se alineaban para entrar y recibir la

\footnotetext{
${ }^{31}$ DEIROS, P. A. Historia del cristianismo, el testimonio protestante en América Latina. Buenos Aires, Argentina: Ediciones del Centro, 2012, p. 359.

${ }^{32}$ WYNARCZYK, H. Ciudadanos de dos mundos, El movimiento evangélico en la vida pública argentina 1980-2001. San Martín, Buenos Aires: USAM EDITA, 2009, p. 121.

${ }^{33}$ Ibid., p. 122.

${ }^{34}$ Ibid., pp. 123-124.
} 
unción, muchas de las cuales quedaban sin entrar esperando por horas otro servicio.

El ministerio de Claudio Freidzon fue de motivación a muchos otros pastores. Entre ellos, la unción fue experimentada por Carlos Mraida, pastor de la Iglesia Bautista del Centro, en la Capital Federal de Buenos Aires. Freidzon oró por él en un servicio, y cuando Mraida vuelve a su iglesia, el siente que el Espíritu Santo le dice: "hoy comienza la unción en la iglesia". ${ }^{35}$ En esta iglesia bautista, la más antigua de Buenos Aires, miles fueron renovados por la experiencia de la unción. Hasta ese tiempo, la iglesia había comenzado una obra misionera, y unos cuatro o cinco pastores salieron de la iglesia. Desde 1992, la iglesia ordenó doce nuevos pastores, más de cien estudiantes se preparan para el ministerio y unas trece obras misioneras se han abierto con planes para abrir otras cincuenta y tres más en el futuro. ${ }^{36}$

Hasta ahora hemos propuesto, luego de analizar el material en los momentos heurístico y crítico, una periodización de los eventos relacionados directamente a la unción. A continuación intentaremos exponer un análisis sociológico y misiológico crítico de este fenómeno a la luz de la historia y de las experiencias que lo caracterizan.

Al considerar el despertar espiritual de la unción en Argentina y en perspectiva de los movimientos precedentes, uno se pregunta ¿cuáles fueron los factores, si los pudiéramos definir de alguna forma, que determinaron estos avivamientos? ¿Qué aspectos hicieron de la iglesia evangélica Argentina un modelo de avivamiento para el mundo? Veremos lo que considero uno de los factores más importantes dentro del campo social, y analizaremos algunos de los resultados de estos avivamientos con la finalidad de dar algunas respuestas a las preguntas planteadas.

\section{El factor encanto-desencanto}

Desde el ángulo sociológico, lo que llamaríamos el factor de "encantodesencanto", y este de forma generalizada, es lo primero que quisiéramos señalar como indicador del pueblo argentino en su búsqueda de Dios y de soluciones a los problemas cotidianos. Hay dos momentos históricos que coinciden con los dos avivamientos argentinos (comienzos de las décadas de los ochentas y

\footnotetext{
${ }^{35}$ RICHARDSON, M. D. Lessons from the Revival on Argentina, p. 71.

${ }^{36}$ Ibid., p. 73. Esta información puede variar en el presente debido a que el año de publicación de la fuente consultada es 1998.
} 
noventas). El comienzo de los ochentas marcó el fin de una dura y sanguinaria dictadura militar y el comienzo de la democracia. El 30 de octubre de 1983 los argentinos votaron a Raúl R. Alfonsín como primer presidente democrático desde el golpe de estado de marzo de 1976. Según Wynarczyk, "la vuelta del país al sistema democrático creó condiciones iniciales favorables para el trabajo de expansión de los evangélicos". ${ }^{37}$ Este encanto con la democracia, sin embargo, no duró mucho dado a las malas condiciones de vida que se suscitaban. El desencanto con la política se mostraba cuando el gobierno tuvo que enfrentar severos problemas financieros y la inflación alcanzó el 688\% para finales de $1984 .{ }^{38}$

Sumado a esto, el otro evento importante de comienzo de los ochentas es la guerra de las Malvinas, iniciada el 2 de Abril de 1982, terminando en una gran humillación luego de 45 días ${ }^{39}$ Claudio Freidzon apunta a este evento como disparador del avivamiento bajo Carlos Annacondia y en sus palabras dice que "fue el dolor, el sufrimiento de nuestra nación, lo que preparó los corazones para el evangelio [dado a que] la guerra de las Islas Malvinas dejó una herida inmensa en el Pueblo". ${ }^{40}$ Como vemos, el avivamiento evangelístico de Annacondia se ve favorecido por la democracia pero está directamente relacionado a los eventos sociales de desencanto por la dictadura y guerra, y luego se suma al desencanto por la llamada "hiperinflación" de 1984. Es justamente allí cuando toman lugar las multitudinarias campañas del evangelista argentino.

Asimismo, en febrero de 1989 el pueblo argentino elige a Carlos Saúl Menem como nuevo presidente, quien al abrazar indiscriminadamente el capitalismo, privatizó las grandes empresas del país. En principios, el encanto brillaba con la baja de la inflación y una aparente estabilidad. Pero el desencanto generalizado aparece ante la imposibilidad de mantener esta presunta estabilidad social tomando lugar una tasa de desempleo mayúscula. Para ilustrar este punto, un estudio sociológico realizado para la Universidad Nacional de Quilmes por los licenciados Jorge Carpio e Irene Novacovsky indica que:

Entre 1991 y 1994 el PBI [producto bruto interno] creció $23 \%$, se incrementó el empleo en un 4\% y la pobreza disminuyó del $25 \%$ al

\footnotetext{
${ }^{37}$ WYNARCZYK, H. Ciudadanos de dos mundos, p. 109.

${ }^{38}$ Ibid., p. 111.

${ }^{39}$ Ibid., p. 112.

${ }^{40}$ FREIDZON, C. Espiritu Santo, tengo hambre de ti, p. 58.
} 
$17 \%$. En ese mismo período la inflación cayó desde el $1000 \%$ anual, alcanzado en 1989, al 3\%. Aun cuando la buena performance de la economía y particularmente el control de la inflación repercutieron favorablemente en mejorar la situación del mercado laboral y los niveles de pobreza, el comportamiento posterior de estos indicadores como resultado de la caída del crecimiento del PBI provocada por impacto del efecto tequila, puso rápidamente de manifiesto los graves problemas estructurales del mercado de trabajo del país y las insuficiencias de las políticas adoptadas para solucionarlos. Durante 1995, en pleno efecto tequila, el PBI cayó un 4.4, el desempleo creció hasta alcanzar niveles del 18\%, sin precedentes históricos en el país, la pobreza volvió nuevamente a aumentar, afectando a los hogares de las capas medias y bajas, con la caída de los ingresos familiares, el incremento de la precariedad y de la desocupación, particularmente de los jefes de hogar y de los jóvenes que procuran acceder al empleo para compensar el deterioro en los ingresos de los hogares. Como resultado de esa situación, el panorama social de los noventa expresa la conflictividad propia de una época de cambio que arrastra un comprometido y prolongado déficit estructural. ${ }^{41}$

Estos episodios, según Wynarczyk, "cerraban una década que se caracterizó por la euforia democrática inicial y un generalizado desencanto final de la ciudadanía con la política y los políticos." ${ }^{42}$ Por lo tanto, el indicador social de encanto-desencanto con la política imperante a comienzos de los noventas, marcado por el desempleo e incertidumbre, se puede poner en paralelo con el avivamiento de la unción en 1992. De esta manera, y en estos dos momentos históricos, la iglesia evangélica argentina alcanza multitudes con un evangelio de poder que respondería a este desencanto generalizado. Un evangelio que en medio de estas incertidumbres sociales les proveía respuestas espirituales a sus problemas del día a día. Analicemos entonces el factor de las multitudes y del poder como efectos de estos avivamientos.

${ }^{41}$ CARPIO, J.; NOVACOVSKY, I. La cuestión social de los 90 en Argentina: Una nueva institucionalidad para las políticas sociales públicas. Disponible en: $<\mathrm{http}$ //www.naya.org.ar/ congresos/contenido/quilmes $>$. Acceso en 30 septiembre de 2013.

${ }^{42}$ WYNARCZYK, H. Ciudadanos de dos mundos, p. 112. 


\section{Las multitudes y el poder}

El pentecostalismo tradicional no había logrado, hasta los eventos de Hicks, una conmoción masiva. La iglesia pentecostal tenía su éxito, pero moderado en comparación a los avivamientos estudiados. Hasta los años cincuenta parecía enfatizar más, dado a la sociedad cambiante en que vivía, una cosmovisión totalmente negativa. El historiador Hans-Jürgen Prien señala este aspecto del pentecostalismo tradicional diciendo que "La liberación de la explotación, del capitalismo o del socialismo, es ofrecida también exclusivamente en categorías individuales, concretamente en forma del apartamiento del mundo en la asamblea de los elegidos [...] como lugar de paz y de la preparación comunitaria del cielo". ${ }^{43}$

El pentecostalismo resultaba ser un lugar de escapatoria y refugio ante la sociedad cambiante y opresora, más que un poder confrontador y capaz de transformar dicha sociedad.

Con la atracción de las masas, el pentecostalismo comienza a buscar su identidad en la sociedad. El teólogo José Míguez Bonino argumenta, siguiendo a otros teólogos y sociólogos, que el pentecostalismo es "un camino de transición hacia la nueva identidad, modos de vida y estructura social, [para que] los fieles puedan ingresar positivamente en la sociedad moderna, adaptándose a ella." ${ }^{44}$ Las características de influencia e inserción social se lograron solo cuando las multitudes comenzaron a hacerse presentes buscando un poder que dice ser superior a todo poder terrenal, y que de hecho, es capaz de enfrentar y transformar los poderes dominantes. Este nuevo paradigma (de los avivamientos de los ochenta y noventa) no pretende que la gente llegue lo mejor posible al cielo, escapando de la realidad (dualismo), sino que busca que las multitudes sean capaces de transformar la sociedad y establecer el reino de Dios en la tierra emulando la realidad celestial "aquí y ahora;" de manera que no escapa de la sociedad sino que se inserta en ella.

El aspecto masivo de esta forma de pentecostalismo no es una característica menor en un país marcado por el dominante trasfondo católico romano. La atracción de las multitudes fue poco en poco quitando el estigma de "secta" al pentecostalismo, y le dio un corte popular atractivo a todos. "Ningún movimiento cristiano puede tener éxito si no conmueve a las masas"

\footnotetext{
${ }^{43}$ PRIEN, H. La historia del cristianismo en América Latina, p. 831.

${ }^{44}$ BONINO, J. M. Rostros del protestantismo latinoamericano. Grand Rapids, MI: Nueva Creación, 1995, p. 62.
} 
decía el misionero y teólogo Juan Mackay, y agregaba: “estoy convencido de que mucho esfuerzo misionero y la obra cristiana en general han errado por tratar de alcanzar exclusivamente a los líderes". ${ }^{45}$ El alcance de las masas ponía a disposición del pueblo (no solo de un grupo selecto de líderes) un poder sobrenatural que permitía lograr un bienestar no provisto por ninguna otra entidad. El poder icónico perteneciente a las élites privilegiadas y opresoras, a partir de los ochentas, pero particularmente desde los noventas, era reinterpretado por la unción para ser utilizado en el ámbito espiritual (ámbito que se consideraba la verdadera realidad de batalla), y era puesto a disposición de toda aquella persona que quiera recibirlo. Todos disponían de poder para transformar la realidad desde lo espiritual y así alcanzar el bienestar. Las reuniones para recibir la unción empoderaba a la gente común, dándoles sentido y seguridad, que antes parecía ser solo el privilegio de pocos. La iglesia, entonces, pasó de ser un pueblo marginal y sectario a ser una comunidad de poder transformador.

Wilma Wells Davies presenta esta realidad diciendo "Aceptando la apreciación de los sociólogos latinos que la religiosidad popular en Latino América es acerca de encontrar soluciones espirituales para los problemas cotidianos, podemos entonces decir que la gente tiene que alcanzar poder espiritual para obtener una solución a sus problemas". ${ }^{46}$

No es de extrañar que, como mencionamos anteriormente, en una sociedad oprimida primeramente por una dictadura militar, y luego por gobiernos democráticos corruptos que privaban de acceso a una vida digna, y abrumados por la inseguridad, la gente busque a un Dios que les provea un poder supremo que ofrezca enfrentar estas injusticias. La opción del cristianismo católico romano rara vez brindaba este poder, solo en ocasión de la manifestación de alguna virgen o santo a los que la gente pedía constantemente; pero quedaba a criterio de estos mediadores conceder una respuesta favorable. Por otro lado, el curanderismo (santería) crecía como una alternativa viable al catolicismo popular. Los curanderos decían tener poder, pero sus medios reflejaban un sincretismo de cristianismo y magia, lo cual preocupaba a muchos. Sumado a esto, las denominaciones históricas no promovían este poder que alcanza milagros porque sus dogmas no se lo permitían. La unción, entonces, era una atracción que prometía contar con un poder sobrenatural para solucionar los

\footnotetext{
${ }^{45}$ Ibid., pp. 57-58.

${ }^{46}$ DAVIES, W. W. The Embattled but Empowered Community, p. 169.
} 
problemas cotidianos. La gente recibía unción e instantáneamente se sentía empoderada para enfrentar cualquier problema. Se sentía fuerte, con autoridad espiritual ante los males que le acechaban.

Según Wilma W. Davies, la cosmovisión de este movimiento, entonces, se caracteriza por una "guerra espiritual", un campo de batalla semejante a un mundo encantado de ángeles y demonios, brujas y exorcistas, y todos estarían de acuerdo que cada aspecto de la vida forma parte de esta batalla. ${ }^{47}$ La manera de ver la realidad cotidiana se convierte en una meta narrativa en donde las pequeñas cosas de la vida son partes de una gran historia; y en donde los problemas del diario vivir son parte de una realidad cósmica, en la cual el individuo ya no es una víctima sino un protagonista, dándole sentido a la vida. ${ }^{48}$

Otro aspecto interesante de este fenómeno es que también atrajo la atención de estratos sociales más elevados. Pablo A. Deiros aclara que estos movimientos son distintos al pentecostalismo clásico, y agrega:

La mayoría de los adherentes al movimiento carismático o neo pentecostal no forman parte de la misma capa social obrera a la que pertenecen los pentecostales clásicos, y mucho menos, proceden de los estratos marginales de donde surge básicamente el pentecostalismo popular latinoamericano. El movimiento carismático encuentra mayor receptividad en la clase media alta de la población urbana. Si bien hay muchos elementos en común entre ambos movimientos, esta diferencia de extracción marca ciertos perfiles distintivos. ${ }^{49}$

Quizá esta característica se deba en primeras instancias, en cuanto al fenómeno de la unción se refiere, a que muchas de las iglesias que abrazaron este mover pertenecen a urbes rodeadas de gente de clase media o media alta (esto difiere de las campañas de Carlos Annacondia que generalmente se realizaban en barrios marginales), tal como la iglesia Rey de Reyes, que se encontraba ubicada en el barrio de Belgrano, un sector pudiente de la ciudad de Buenos Aires. Éstas son iglesias de ciudades céntricas, no marginales. Es

\footnotetext{
${ }^{47}$ Ibid., p. 166.

${ }^{48}$ Ibid., p. 166.

${ }^{49}$ DEIROS, P. A.; MRAIDA, C. Latinoamérica en llamas, historias y creencias del movimiento religioso más impresionante de todos los tiempos. Nashville, TN: Caribe, 1994, p. 263. Esta taxonomía de neo-pentecostalismo también es seguida por WYNARCZYK, H. Ciudadanos de dos mundos, p. 123.
} 
por esto que la unción simpatizó, no solo con el pueblo marginal, sino también con la sociedad más acomodada. Estos estratos sociales ahora encontraban un cristianismo que se amalgamaba con su estilo de vida. Ya la pobreza no tenía que ser abrazada. De hecho, con frecuencia se escuchaba a pastores o evangelistas echar fuera espíritus de escasez o pobreza (algo que para muchos va en contra del estilo de vida de Jesús y aun de los escritos de los apóstoles; pero abordar este aspecto teológico requeriría un análisis que no podemos proveer en este marco). Aquellos que estaban mejor ubicado en la sociedad, encontraban en la unción un poder para progresar aún más, o bien, para un mejor vivir en medio de un mundo inseguro. La unción les daba el poder para conservar sus familias, ser mejor empleados o empleadores, y, acorde a este testimonio, presentaban el evangelio.

En cuanto al mensaje proclamado (kerigma) el foco seguía siendo salvación y milagros (que con Cabrera y Annacondia se enfatizaba), pero además de esto, se hablaba de bienestar, de un poder para cambiar la realidad y conquistar promesas. Se enfatizaba que Dios tiene bendiciones para la gente hoy, y que se puede tener el poder para alcanzarlas. Una de las palabras clichés en las oraciones del pastor Freidzon era su enfático ¡ahora! Se buscaba que Dios haga algo "ahora," en ese momento, que supla la necesidad cotidiana, haciendo del reino de Dios algo palpable en el presente, y no solo en un futuro lejano. Una suerte de escatología inaugurada. Es por estos puntos mencionados anteriormente, que el antropólogo y sociólogo Daniel Míguez observa lo siguiente en relación a esta forma de pentecostalismo en Argentina:

En términos doctrinales, este nuevo tipo de pentecostalismo pondría menos énfasis en la santificación y el bautismo con el Espíritu Santo y más énfasis en la sanidad, la teología de la "prosperidad" y guerra espiritual. Hay menos demanda de compromiso con la vida congregacional, y asimismo, más uso de los medios masivos de comunicación y un manejo de corte más empresarial de la iglesia. ${ }^{50}$

A esto, Daniel Míguez agrega que esta es la razón por la que algunos autores llaman a estas iglesias "agencias religiosas" o "industrias religiosas". La unción hizo que las iglesias crezcan de manera superlativa y así se conviertan, casi sin buscarlo, en mega-iglesias. Lo llamativo de estas megaiglesias y sus enormes estructuras, lleva a la conclusión lógica que deben ser

${ }^{50}$ MíGUEZ, D. Spiritual Bonfire in Argentina, p. 28. 
manejadas como grandes empresas. A modo de ejemplo, la iglesia Rey de Reyes actualmente construyó un auditorio para unas 2.500 personas sentadas, de primera calidad. Su crecimiento ha sido tan extraordinario, que este proyecto fue posible, aun en medio de un barrio que es muy difícil lograr tremenda estructura. Cuenta, además, con diez pisos de oficinas. Y así se han levantado iglesias como éstas en toda la nación después de la unción.

Sin embargo, habría que ser honestos en que sería imposible administrar semejantes estructuras si no existiera una organización del tipo empresarial. Por lo tanto, esta crítica de Míguez debiera ser balanceada con las motivaciones y los objetivos del ministerio desarrollado. Si el ministerio está enfocado en extender el reino de Dios, a priori no habría problema con la estructura empresarial. Si al contrario es para satisfacer un egocentrismo y riquezas personales, allí será condenable. Y de hecho, este parece ser uno de los peligros más latentes en estos círculos.

Asimismo, debemos separar algunos puntos que Míguez parece mezclar, quizás agregando características que han sido propias de un neopentecostalismo $^{51}$ norteamericano, pero que, en líneas generales, no fue el caso de Argentina. La era de la unción marcó el comienzo y la continuidad de iglesias masivas. Anteriormente a Claudio Freidzon, ya mencionamos a Omar Cabrera con Visión de Futuro, cuya iglesia era multitudinaria; y deberíamos agregar a la lista, para hacer justicia a la historia, al pastor Héctor Aníbal Giménez, quien llegó a ofrecer servicios todos los días de la semana a toda hora. Su iglesia, Ondas de Amor y Paz, en la Capital Federal de Buenos Aires, ha llegado a congregar literalmente multitudes (Pablo Deiros habla de más de 120.000 fieles; ${ }^{52}$ mientras que Richardson duplica la cantidad a 250.000 miembros, y sumado a esto, 150 anexos). ${ }^{53}$ Por problemas familiares, su ministerio no continuó con esta intensidad desde 1994. Lo llamativo de la

\footnotetext{
${ }^{51}$ En nuestra apreciación, el término neo-pentecostalismo no haría justicia a la historia y experiencia de la unción en Argentina, primeramente debido a las connotaciones negativas que están aparejadas a esta nomenclatura y que son características de corte anglosajón (enfático evangelio de prosperidad, falta de compromiso, confesión positiva, etc.). Es por esto que no resulta fácil encontrar una definición que encuadre el mover de Dios que tomó lugar en Argentina desde 1992. De esta falta de vocabulario especifico, se usan muchos términos, de los que preferimos usar avivamiento o despertar espiritual, aunque también requeriría definiciones más precisas.

${ }^{52}$ DEIROS, Pablo A. Historia del cristianismo, p.175.

${ }^{53}$ RICHARDSON, M. D. Lessons from the Revival on Argentina, p. 60. Estas cifras son mencionadas por Richardson en su tesis y fueron tomadas de la propia publicidad del ministerio de Giménez.
} 
unción, es que a partir de estas instancias el fenómeno se multiplicó por toda la nación, y ya no era solo un pastor capaz de llenar templos grandes, sino que toda aquella persona que recibía este poder, era potencial candidato a convertirse en un instrumento para atraer las masas (como lo fue el joven evangelista Dante Gebel, quien a sus 27 años ya llenaba estadios con jóvenes).

Lo que Míguez parece generalizar, entonces, es que esta era de megaiglesias derivó en desinterés por santidad y compromiso. En otras palabras, lo que sostiene es que el evangelio se tornó más materialista y menos espiritual. Lo que quisiéramos argumentar aquí, solo a modo de observación al enunciado de Míguez, es que este no ha sido el caso de la iglesia evangélica en Argentina. Al contrario, la unción llevó a un fuerte compromiso cristiano. A la iglesia Rey de Reyes, por ejemplo, le sobraban obreros para el ministerio. La santidad se respiraba en el ambiente, y la santificación era algo siempre predicado por el pastor Freidzon, como también por otros ministros. El mensaje se pudiera decir que era más de victoria, pero la teología de la prosperidad no ha sido un mensaje de sobre énfasis como se suele entender en el contexto anglosajón. Tampoco lo era un "evangelio light" (liviano). El compromiso y la santidad eran bastiones del kerigma bajo el mover de la unción.

\section{Conclusiones y observaciones finales}

Esta investigación histórica desde el ángulo de la iglesia evangélica pentecostal y los sucesivos avivamientos nos muestra a primera vista la importancia y el saldo positivo, tanto en lo social como en lo eclesiástico, que tuvieron estos eventos. Estos avivamientos no proveían dogmatismos, sino experiencias que daban esperanza a multitudes. Hemos visto que esta esperanza está basada en la oportunidad de recibir milagros y liberación en lo espiritual. La época de la unción proveía poder para que todos sean protagonistas en esta batalla espiritual con la promesa de victoria. Multitudes encontraron en este poder la salida a la opresión de la época, una liberación espiritual que se reflejaba en lo cotidiano.

La unción marcó el comienzo de una vitalidad espiritual que nunca había vivido la iglesia argentina. Este despertar tuvo repercusiones internacionales (Toronto, por ejemplo - y el pastor Freidzon viajó por todo el mundo compartiendo esta experiencia). El vigor espiritual que la iglesia evangélica argentina experimentó motivó a salir de las cuatro paredes y llevar el evangelio del Reino a la sociedad. A predicar un evangelio de poder, capaz de transformar 
las vidas más difíciles y las situaciones más conflictivas. Este aporte es sumamente positivo, más cuando lo podemos ver a la luz de la historia en general y también desde un ángulo bíblico. El dogmatismo no ha sido central ni en la Biblia ni en la historia. Pero si la experiencia de Dios. Si lo ha sido la vivencia de un evangelio de poder. Esto fue lo que enfatizó este mover: la experiencia. Dios es real, se puede experimentar, el sigue hablando hoy.

Asimismo, esta vitalidad no dividió la iglesia evangélica, como ha ocurrido en el norte anglosajón (quizás debido a que allí la presencia conservadora ha sido mucho más fuerte y defensiva que en Argentina). De hecho, la unción trajo unidad pastoral. Las iglesias, conservando sus credos, se unieron en esta experiencia renovadora. Cuando en otros lugares se seguían peleando por doctrinas, en Argentina, pastores e iglesias de diferentes banderas teológicas se unían bajo el techo de la unión. Es rescatable, entonces, que el lenguaje de esta experiencia se encuentre impregnado en las variadas denominaciones, incluso católicos romanos, siendo éste un punto de encuentro y unidad indispensable para el testimonio cristiano al mundo.

Del otro lado del péndulo en la evaluación de la unción, si la experiencia no va de la mano de la reflexión el mover del Espíritu tiende a menguar, o peor, a estructurarse; y bien pudiéramos decir que termina institucionalizándose. Tal como la fe sin obras es muerta, la experiencia sin reflexión tiende a morir bajo una estructura infructuosa. Y si algo hay débil en estos avivamientos es la reflexión. Se teme que por reflexionar teológicamente se mate al Espíritu, cuando justamente sería al revés. La falta de reflexión tiende justamente a llevar a dogmatismos ciegos. La reflexión, en cambio, provee una teología saludable que permite continuar con el mover, y a su vez podar las ramas para que lleve más frutos.

Este avivamiento tiene sus enemigos. Figuras de caudillos, que se encumbran en lo más alto, concentración de poder, las riquezas. Peligros que amenazaron con apagar la vitalidad en toda la historia, y que con eficacia lo han logrado. Basta con dar una mirada al fariseísmo bíblico, al constantinismo, al siglo de hierro, a la reforma. Cuando no se ha reflexionado bíblicamente a la luz de la experiencia y de la realidad imperante se ha perdido el hilo de lo que había nacido con vigor y vitalidad espiritual. La combinación constante de estos dos ingredientes es vital. Jesús dijo en cierta ocasión para responder sobre la posibilidad de resurrección: "erráis ignorando las escrituras y el poder de Dios" (Mateo 22:29). Dos ingredientes claves para todo mover: escrituras y poder. La unción proveyó el poder. Debería ser tiempo de reflexionar 
seriamente en las escrituras para que lo que empezó como algo genuino no corra la suerte de terminar como muchos otros avivamientos, en monumentos a la falta de balance y comunión entre la reflexión y la experiencia. Una falta de balance que ha desembocado en un objetivismo marcado por sistemas teológicos rígidos o bien en un subjetivismo en donde se endiosa lo místico.

En resumen, el saldo que la unción ha dejado es sumamente positivo. Cientos de miles se convirtieron a Jesucristo. Muchos cristianos y líderes salieron de un letargo espiritual que amenazaba su caminar con Dios. La santidad se convirtió en un valor deseable para el cristiano. La oración y el ayuno eran motores para mantener e incrementar esta unción. La iglesia evangelizaba como poco se había visto antes. Podemos confiadamente decir que Dios visitó Argentina. ¿Los motivos? De acuerdo a este estudio, podemos delinear algunos factores que se conjugaron para que estos avivamientos tengan lugar. La inestabilidad social trajo un desencanto generalizado. En esos momentos claves $(50 \mathrm{~s}, 80 \mathrm{~s}, 90 \mathrm{~s})$, ciertas figuras aparecían predicando un evangelio de poder. Este poder fue liberador y, por lo tanto, deseable por muchos. Asimismo, el deseo ferviente que existía en ciertos líderes cristianos por un cristianismo diferente, relevante, por una iglesia pujante, que produzca cambios, que atraiga multitudes, y así también que impacte la sociedad, fue un motor que los propulsó a salir de su comodidad y a moverse de lo que conocían. El deseo de ver a un Dios sobrenatural obrando poderosamente en su medio fue clave para estos líderes. Estaban convencidos de este poder. Estaban seguros que Dios puede transformar todo una nación. Y actuaron en consonancia a esta convicción. No midieron los costos ni la opinión popular. Se midieron con un desafío imposible para los hombres. Obligaron a Dios a actuar. Fueron intrépidos. Como resultado, hoy la iglesia evangélica goza de respeto público. Ya nadie se atreve a llamarla una secta. Y las denominaciones históricas que en un principio miraban de reojo la unción, hoy la buscan, hoy la abrazan, hoy dicen tener ministerios ungidos. Si vamos mas allá, hoy día hasta el catolicismo romano fue afectado por la unción, cuyo vicario de Cristo actual es un jesuita directamente influenciado de manera positiva por estos movimientos.

El desafío será mantener esta unción. Seguir buscándola. Aprender de los errores que la maestra historia nos enseña. Y esto se logrará reflexionando junto a aquellos que siguen sedientos de ver a Dios obrar y junto a aquellos que no quieren que un avivamiento se sepulte. Habrá que buscar al Espíritu Santo y reflexionar junto al Espíritu Santo. 


\section{Referencias bibliográficas}

BONINO, José Míguez. Rostros del protestantismo latinoamericano. Grand Rapids, MI: Nueva Creación, 1995.

CARPIO, Jorge; NOVACOVSKY, Irene. La cuestión social de los 90 en Argentina: Una nueva institucionalidad para las políticas sociales públicas. Disponible en: <htttp://www.naya.org.ar/congresos/ contenido/quilmes $>$. Acceso en 30 septiembre de 2013.

DAVIES, Wilma Wells. The Embattled but Empowered Community, Comparing Understanding of Spiritual Power in Argentine Popular and Pentecostal Cosmologies. Leiden, The Netherlands: Kominklijke Brill, 2010.

DEIROS, Pablo A. Historia del cristianismo, el testimonio protestante en América Latina. Buenos Aires, Argentina: Ediciones del Centro, 2012.

DEIROS, Pablo A. Historia del Cristianismo en América Latina. Buenos Aires, Argentina: Fraternidad Teológica Latinoamericana, 1992.

DEIROS, Pablo A.; MRAIDA, Carlos. Latinoamérica en llamas, historias y creencias del movimento religioso más impresionante de todos los tiempos. Nashville, TN: Caribe, 1994.

FREIDZON, Claudio. Espiritu Santo, tengo hambre de ti. Nashville, TN: Caribe-Betania, 1996.

GRAMS, Rocky. In Awe in Argentina. Lake Mary, FL: Creation House, 2006.

HICKS, Tommy. Millions Found Christ, Greatest Recorded Revival. Hollywood, CA: International Headquarters of Tommy Hicks, 1956.

MÍGUEZ, Daniel. Spiritual Bonfire in Argentina, Confronting current Theories with an Ethnographic Account of Pentecostal Growth in a Buenos Aires Suburb. Amsterdam, Holanda: CEDELA, 1989.

PRIEN, Hans Jürgen. La historia del cristianismo en América Latina. Salamanca, España: Ediciones Sígueme, 1985.

RICHARDSON, Michael Donald. Lessons from the Revival on Argentina. Tesis para un Doctorado em Ministerio. Fuller Theological Seminary, Pasadena, CA, 1998. 
ROBECK Jr., C. M. The Azusa Street Mission and Revival, The Birth of the Global Pentecostal Movement. Nashville, TN: Thomas Nelson, 2006.

SARACCO, José Norberto. Argentine Pentecostalism, Its History and Theology, Tesis de PhD, Universidad de Birmingham, 1989.

WAGNER, C. Peter; DEIROS, Pablo A. Manantiales de avivamiento: lo que el Espiritu dice a través del avivamiento en Argentina. Nashville, TN: Editorial Caribe Betania, 1998.

WYNARCZYK, Hilario. Ciudadanos de dos mundos, El movimiento evangélico en la vida pública argentina 1980-2001. San Martín, Buenos Aires: USAM EDITA, 2009.

Roney de Seixas Andrade

Doutor em Ciência da Religião - Universidade Federal de Juiz de Fora Doutorado Sanduíche no Fuller Theological Seminary, Pasadena - CA Professor na Faculdade Sul Fluminense

Volta Redonda / RJ - Brasil E-mail: roneyseixas@yahoo.com.br

J. Gabriel Raimondo Mestre em Teologia - Fuller Theological Seminary, Pasadena - CA Professor na Escola de Teologia da Azusa Pacific University Azusa / CA - E.U.A E-mail: gabrielraimondo@gmail.com

Recebido em: 29/03/16

Aprovado em: 23/05/16 